\title{
Design and installation of a novel multi-point measurement system for a renewable energy grid
}

\author{
J. Bruna ${ }^{1}$, J.J. Melero ${ }^{1}$, D. Cervero ${ }^{1}$, R. Caballero ${ }^{2}$, J. Díaz-de-Aguilar ${ }^{2}$ and M. Neira ${ }^{2}$ \\ ${ }^{I}$ CIRCE - University of Zaragoza, Zaragoza, Spain \\ C/ Mariano Esquillor Gómez, 15 - Zaragoza 50018 (Spain) \\ Phone:+34976762402,e-mail:jbruna@unizar.es/melero@unizar.es/dcervero@unizar.es \\ ${ }^{2}$ CEM (Centro Español de Metrología), Madrid, Spain \\ C/ del Alfar, 2 - Tres Cantos, Madrid (Spain) \\ Phone: +34918074 715, e-mail: rcaballero@cem.minetur.es/jdiaz@,cem.minetur.es / mneirar@,cem.minetur.es
}

\begin{abstract}
New power generation systems will be characterized by multiple small-scale units, integrating nonconventional or renewable sources, such as wind turbines, photovoltaic power plants or even hydrogen generation and storage. Monitoring this kind of installations is of vital importance for security of supply and efficiency issues. The integration of these energy sources with the actual centralized ones involves great challenges for engineers to correctly plan the grid without any problem of stability. Therefore, successful implementations of smart electrical networks require the development of robust systems of analysis for electrical parameters. This paper shows a multipoint measurement system, installed in a relevant renewable-supplied technology park, ready to monitor all power quality parameters and their influence into the distribution grid. Important results will be shown applied to the existent power quality (PQ) at the technology park.
\end{abstract}

\section{Key words}

Grid stability, power quality, electrical perturbances, measurement system, renewable energies

\section{Introduction}

Nowadays, the electrical energy network and thus the methods by which electrical energy is generated are changing. The idea is a radical change in the distribution configuration. Generating resources are being connected to the distribution network rather than the transmission grid (considered as the actual backbone of the electrical grid). The integration of renewable energy is causing problems in the control of power flow, power quality and protection systems $[1,2]$. Because of that, it is necessary to develop systems for monitoring this on-site generation accurately.

This paper is organized as follows:

- Identification of the renewable site.

- Description of the measurement system: hardware and software.
- Description of the measurement system installation.

- Measurement campaign and results.

This paper begins first with the selection of the appropriate location to perform a singular measurement campaign with different types of renewable energy sources. Once the locations have been selected, a slight description of the measurement system is given (HW and SW). Finally, the results concerning to some PQ parameters will be shown. These advanced on-site measurement campaigns will establish and refine methodologies which will become industry standards for future grid design validation and PQ assessments.

This description is not only valid for this concrete case but also for any other on-site installation susceptible to be analysed. The installation of more measurement points makes possible the study of larger electrical grids as well as the transmission and propagation of disturbances through them.

\section{Site description}

Walqa is a technology park located near Huesca (Spain). It integrates several renewable sources of energy $\left(\mathrm{H}_{2}\right.$ production, wind and photovoltaic energy). The mix of these three types of generation makes possible to see the effects on end-users. The sources fed a closed ring where end-users are connected $(15 \mathrm{kV} / 690 \mathrm{~V})$.

The available renewable sources are the following:

- 3 wind turbines $(635 \mathrm{~kW})$

- 2 photovoltaic power plants $(200 \mathrm{~kW})$

- 1 hydrolyser $(65 \mathrm{~kW})$

The nominal distribution voltage level corresponds to $15 \mathrm{kV}$ while the low voltage level in the generation side is $690 \mathrm{~V}$. 
As previously stated, the final aim of this study is to quantify how the different distributed generation units affect the global power quality, PQ. Although seven different points were identified, some of them correspond to the same electrical circuit. With this premise, four different measurement points (Vestas wind turbine, Enercon wind turbine, photovoltaic plants and an office building) were established for the three sources and one for the customer side (Figure 1).

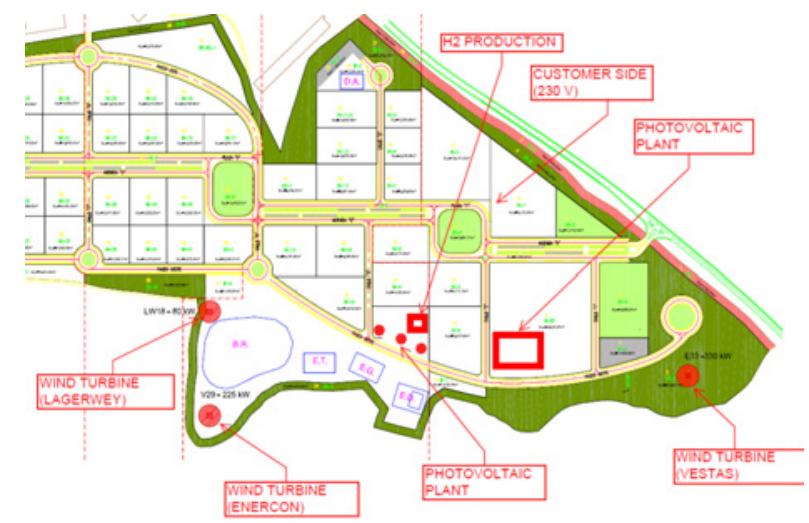

Figure 1. Measurement point distribution

All measurement points were synchronized to get traceable results between them according to the latest PQ standards. $[3,4]$.

\section{Measurement system}

The development of the measurement system was divided into two parts:

- HARDWARE: It includes all the parts that make possible the reading of voltages by the system (transducers, data acquisition, synchronizing circuit...).

- SOFTWARE: All algorithms for PQ measurements.

\section{A. HARDWARE}

The system is based on a mini-ITX motherboard. All the physical parts are mounted inside the mini-ITX chassis that contains other elements such as the voltage conditioning stage, the data acquisition (DAQ) card or the hard disk drive (HDD).

Additionally, a global positioning system (GPS) card synchronizes the system's time of all points of measurement with universal time (UTC). The following paragraphs describe the most important parts of the system:

\section{VOLTAGE CONDITIONING STAGE}

It steps down the voltage from the generation units (up to $1000 \mathrm{~V})$ to DAQ card input voltage levels $( \pm 5 \mathrm{~V})$. It is performed using resistive dividers and isolation amplifiers for security reasons.

\section{DAQ CARD}

NI-PCI 6220 card allows up to 8 differential channels to be connected to the system, providing high-resolution and accuracy for PQ measurements (16 bits). The differential mode was selected because of the lead length (greater than 3 meters) and the noisy environment where measurements take place.

\section{$\underline{\text { GPS }}$}

A Navman Jupiter TU60-D120 works as the timing engine for the system. Its $10 \mathrm{kHz}$ output signal, available from the receiver and phase-coherent with the 1PPS signal, is used to regulate a voltage-controlled crystal oscillator (VCXO). This electronic oscillator generates the signal $(10 \mathrm{MHz})$ needed to both lead the PLL circuit and feed with the UTC-synchronized signal to the DAQ card. Therefore, it constantly adjusts its output phase and frequency to match (and thus lock) the reference clock signal from the GPS [5].

\section{B. SOFTWARE}

All software applications are developed on GNU/Linux, programmed in $\mathrm{C}$ language and modularly implemented. This makes easy the adaptation of the development to the power quality measurement methods standard [6]. This standard establishes fundamental parameters to be tracked and analyzed for the emission of accredited certificates:

\section{Power frequency \\ 2. Magnitude of the supply voltage \\ 3. Flicker \\ 4. Supply voltage swells and dips \\ 5. Voltage interruptions \\ 6. Transient voltages \\ 7. Supply voltage unbalance \\ 8. Voltage harmonics \\ 9. Voltage interharmonics}

All of these parameters were implemented as unique software modules. Each one of these modules can be enabled or disabled depending on user's needs. The system is also capable of recording waveform not only when the voltage event sub-module triggers but also when the user activates this functionality.

DAQ card starts acquiring data with the master clock from GPS. This ensures that all data, from all measurement points, have the same reference time. Later, data are processed by the different algorithms, storing the results into a MySQL database.

Every measurement system has connection with a remote host via Wi-Fi. Data from each system is sent and stored by the host server into 4 different database tables corresponding to flicker, events, RMS calculations (frequency, unbalance, magnitude of voltage...) and harmonics/interharmonics. This structure of storage helps users to perform a quicker and easier analysis.

Based on the foregoing considerations, the local software architecture is depicted in Figure 2. 


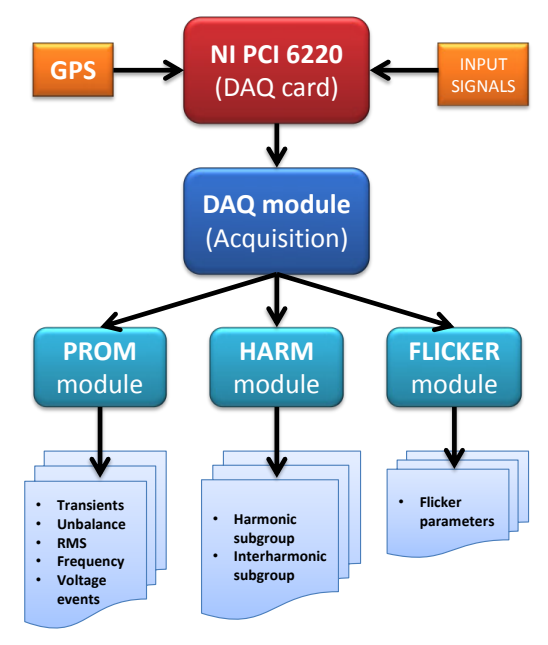

Figure 2. Measurement system flowchart

This software architecture method builds a measurement system with sufficient flexibility to face up to any problem with the incorporation of new algorithms or their modification.

The system also incorporates one ethernet module that makes possible its connection to the communications network. This is especially important for fetching remote data or when some configuration change is needed.

The assembled measurement system is shown in Figure 3.

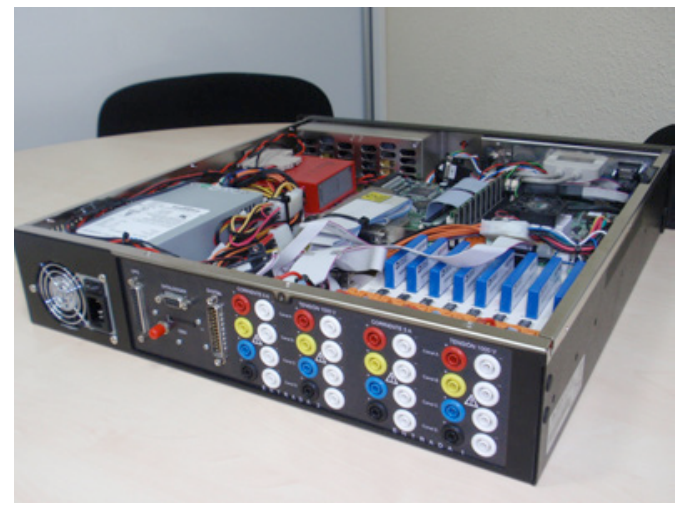

Figure 3. Measurement system

\section{Verification and calibration}

The workflow for the developing of a new measurement system comprises its verification, not only involving hardware but also software verification. The calibration of the 9 algorithms developed was performed according to IEC 61000-4-30:2008 guidelines. The calibrations took place at the LME-CIRCE (Laboratorio de Metrología Eléctrica) from CIRCE and the University of Zaragoza. This is an accredited laboratory from ENAC (EA full member) that meets all the requirements of the ISO/IEC 17025 regulations. All tests were generated by means of a traceable Fluke 6100A Electrical Power Standard.

Some calibration results for one measurement system and one channel are shown in Table 1. These have also been compared with the limits shown in the standard [6].
Table 1. Calibration results

\begin{tabular}{cccc}
\hline Algorithm & $\begin{array}{c}\text { Maximum calibration } \\
\text { uncertainty }\end{array}$ & $\begin{array}{c}\text { IEC } \\
\text { Limits [6] }\end{array}$ & Results \\
\hline $\begin{array}{c}\text { Power } \\
\text { frequency }\end{array}$ & $\pm 0.006 \mathrm{~Hz}$ & $\pm 0.010 \mathrm{~Hz}$ & PASS \\
Voltage & $\pm 0.07 \%$ & $\pm 0.100 \%$ & PASS \\
Current & $\pm 0.10 \%$ & $\mathrm{~N} / \mathrm{A}$ & $\mathrm{N} / \mathrm{A}$ \\
Flicker & $\pm 0.506 \%$ & $\pm 5.000 \%$ & PASS \\
\hline
\end{tabular}

All the uncertainties were calculated according to the internal calibration procedure of the laboratory for Power Quality Analyzers. This procedure was written following the international standard specifications $[4,6]$. Other PQ parameters such as voltage events, voltage unbalance, harmonics or interharmonics also meet the IEC uncertainty requirements.

Besides, the assembled measuring device was tested before and after the on-site use. Some different tests were carried out to check the insulation and immunity performance, according to the corresponding standards [717], obtaining good results.

\section{Measurement system installation}

Each one of the systems, for this specific application, monitors 3 voltage and 3 current channels. Voltage channels were wired to the power transformer's low voltage side $(690 \mathrm{~V})$ via fuse boxes for maintenance and safety reasons.

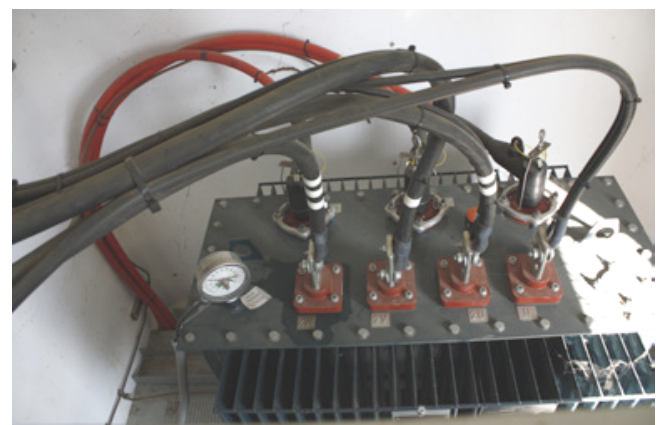

Figure 4. Power transformer

Current measurements were carried out using 500/5 A and 250/5 A split-core current transformers (class 0.5) as transducers [18]. See Figure 5.

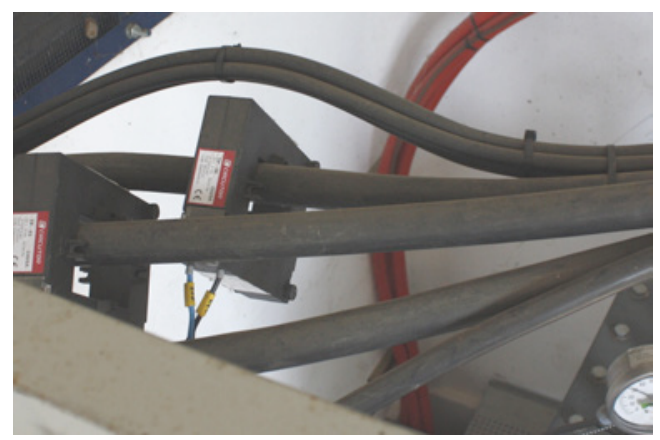

Figure 5. Split-core transformers 
One additional single-phase measurement point was chosen at an office building for power quality monitoring $(230 \mathrm{~V})$.

\section{Measurement campaign}

In order to assess the Power Quality for the on-site installation, the measurements were conducted for at least 7 months. As previously mentioned, all the results are stored into a remote MySQL database for an easy post-processing analysis. Near $800 \mathrm{~GB}$ were collected during the period corresponding more than $20 \mathrm{~GB}$ to waveforms due to event triggers.

The following figures show some examples of the existent Power Quality.

Figure 6 shows an example of the results obtained for the magnitude of voltage supply calculated each $200 \mathrm{~ms}$ and refreshed each $1 / 2$ cycle for the three-phase system of four measurement points. It can be seen that it will be easy to identify any propagated disturbance when data from different measurement points are compared at the same time (GPS time reference).
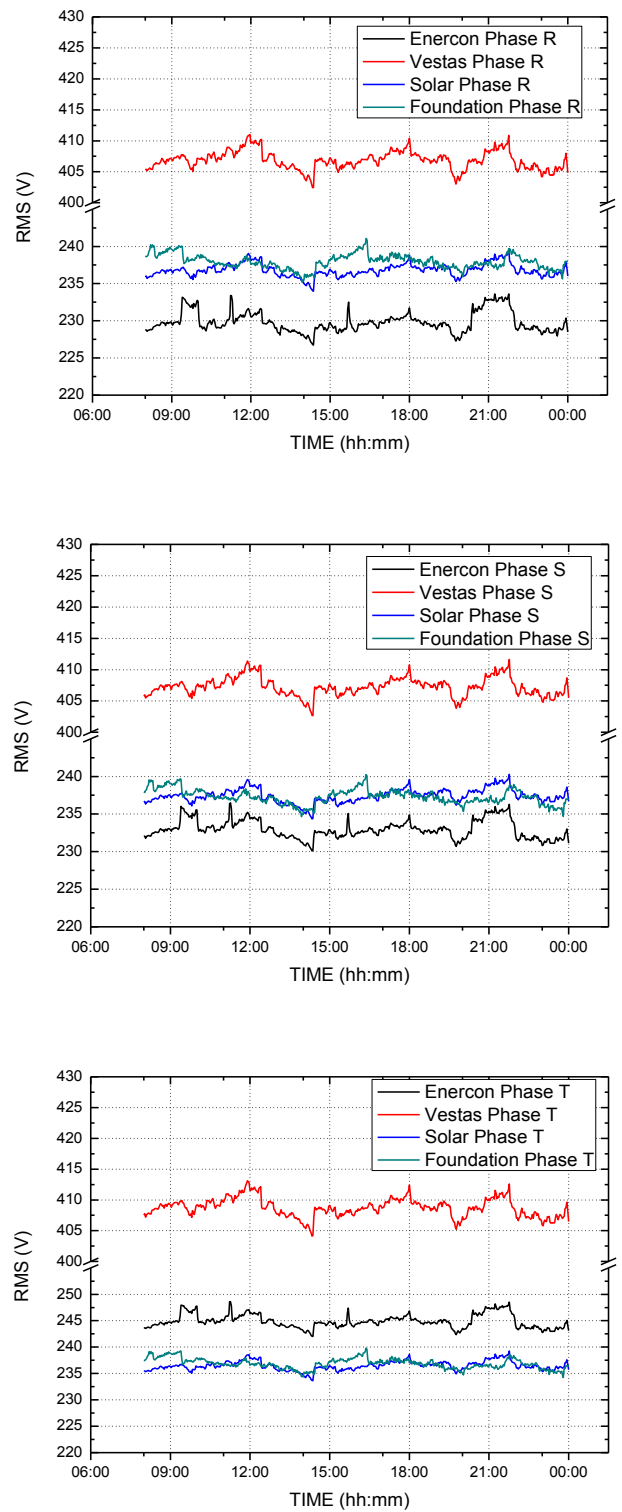

Figure 6. Magnitude of voltage supply comparison
Figure 7 illustrates some spikes at the R-phase that appear when the Enercon's power control system enables wind turbine generation. Once the wind turbine stops, its voltage at the LV busbars remains unperturbed (identified when current waveform drops near zero).

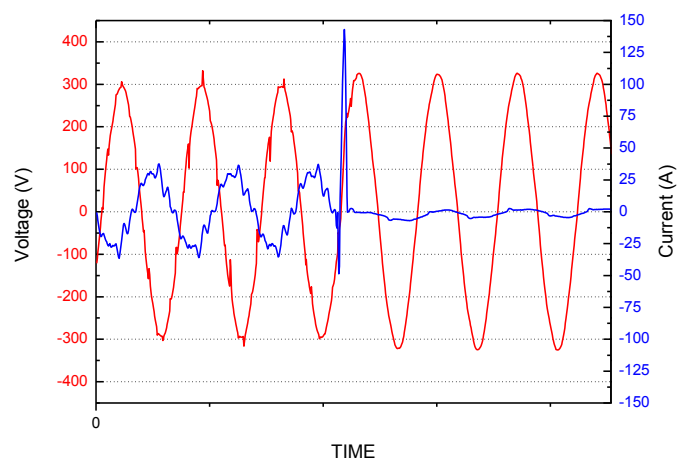

Figure 7. Enercon voltage waveform

Frequency stability through the grid can also be tracked when the results from the frequency algorithm are plotted. By analyzing the data obtained from each individual measurement system, we obtain a clear idea of how renewable energy sources affect the overall PQ as showed in Figure 8.

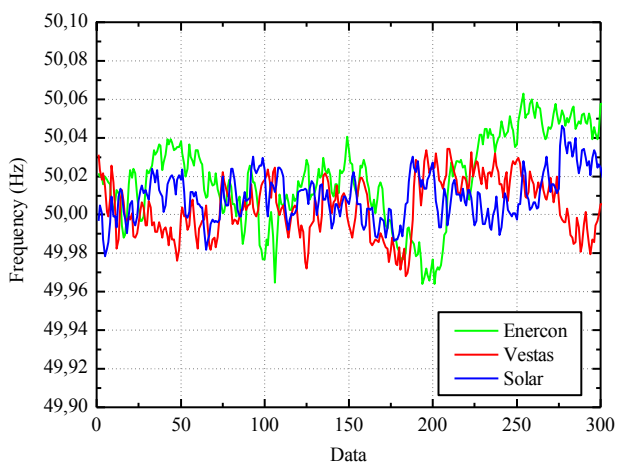

Figure 8. Power frequency comparison

Another important parameter to be calculated is flicker. Pst values for the three renewable energy points plus the customer side are represented in Figure 9. Higher values at the Foundation building are justified because of the great number of electronic devices inside the building (laptops, CFL lamps, the hydrolizer...).

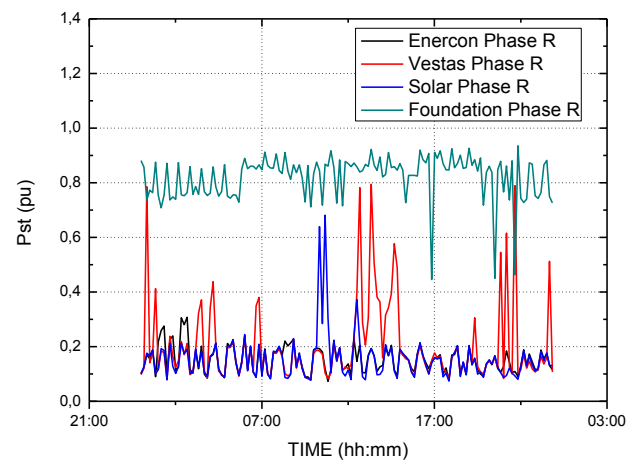

Figure 9. Flicker content 


\section{Conclusions}

In this paper, the design and installation of a novel multipoint measurement system was presented. The proposed scheme includes first the design and implementation of a fully functional measurement system with a very accurate time base, synchronized with UTC time through a GPS module. This functionality allows the user to compare easily data from different geographical places; so electrical disturbances can be identified and hence minimized (installation of capacitor batteries, topology modification...).

In more detail, the complete measurement systems were validated and calibrated according to the latest PQ analyzer calibration standards. The calculated uncertainties, all of them below the required ones, make possible that these measurement devices will be considered like IEC Class-A precision systems. Therefore, they can be used in precise PQ assessments.

Finally, 4 measurement systems were deployed. Data from all these locations were harvested for having enough results to be compared. The special topology of the grid and the integration of several types of renewable energy sources provide an excellent scenario to test and verify the stability of this kind of singular electrical grids. At this moment, the obtained results are being studied. This work will serve as the starting point for analyzing more complex networks, especially those with important generators distributed over the installation to be studied.

\section{Acknowledgment}

The research leading to the results described in this paper is part of the European Metrology Research Program (EMRP), which is jointly funded by the EMRP participating countries within EURAMET and the European Union.

\section{References}

[1] C.XiaoLing, Z.JiFen, L.ChuanWei, H.WeiPing, and W.LiWei, "Design and Implementation of Relay Protection Fault Information Intelligent Analysis System in Smart Grid", IEEE. 2011 The International Conference on Advanced Power System Automation and Protection, 2011.

[2] F.Kawano, G.P.Baber, P.G.Beaumont, K.Fukushima, and T.Miyoshi, "Intelligent Protection Relay System for Smart Grid", 10th IET International Conference on Developments in Power System Protection (DPSP 2010), 2010.

[3] "IEC 61000-4-15:2008 Ed.2.0 - Electromagnetic Compatibility (EMC) - Part 4-15: Testing and Measurement Techniques - Flickermeter - Functional and Design Specifications", 2010.

[4] "EN 50160: Voltage Characteristics of Electricity Supplied by Public Electricity Networks", 2007.

[5] J.Miller (27/01/12),"A Simple GPS Stabilised $10 \mathrm{MHz}$ Oscillator","http://www.jrmiller.demon.co.uk/projects/mi nistd/frqstd0.htm", 2008.
[6] "IEC 61000-4-30 Ed2.0 - Part 4-30: Testing and Measurement Techniques - Power Quality Measurement Methods", 2008.

[7] "IEC 61326-1 - Electrical Equipment for Measurement, Control and Laboratory Use - EMC Requirements - Part 1: General Requirements", 2005.

[8] "EN 55011 - Industrial, Scientific and Medical Radiofrequency Equipment - Radio Disturbance Characteristics - Limits and Methods of Measurement", 1998.

[9] "IEC 61000-3-2 - Limits for Harmonic Current Emissions", 2000.

[10] "EN 61000-3-3 - Limitation of Voltage Changes, Voltage Fluctuations and Flicker in Public Low-Voltage Supply Systems, for Equipment With Rated Current $<=$ 16 A Per Phase and Not Subject to Conditional Connection", 1997.

[11] "EN 61000-4-2 - Personnel Electrostatic Discharge Immunity", 1995.

[12] "EN 61000-4-3 - Electromagnetic Compatibility (EMC) - Testing and Measurement Techniques - Radiated, Radio-Frequency, Electromagnetic Field Immunity Test", 2006.

[13] "EN 61000-4-4 - Electromagnetic Compatibility (EMC) -Testing and Measurement Techniques - Electrical Fast Transients / Burst Immunity Test", 1995.

[14] "EN 61000-4-5 - Electromagnetic Compatibility (EMC) - Testing and Measurement Techniques - Surge Immunity Test", 1995.

[15] "EN 61000-4-6 - Electromagnetic Compatibility (EMC) - Testing and Measurement Techniques - Immunity to Conducted Disturbances Induced by Radio Frequency Fields", 1996.

[16] "EN 61000-4-8 - Electromagnetic Compatibility (EMC) - Testing and Measurement Techniques - PowerFrequency Magnetic Field Immunity Test", 1993.

[17] "EN 61000-4-11 - Electromagnetic Compatibility (EMC) - Testing and Measurement Techniques Voltage Dips, Short Interruptions and Voltage Variations Immunity Tests", 2004.

[18] "IEC 60044-1 Ed.1 - Instrument Transformers - Part 1: Current Transformers", 1996. 